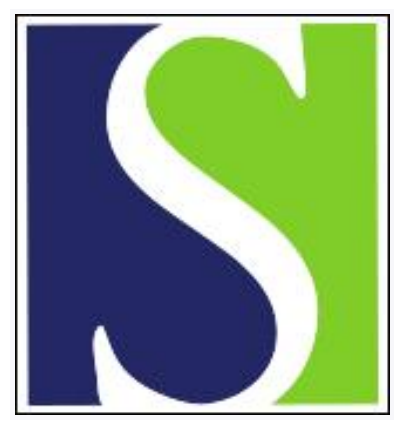

Scand J Work Environ Health 2012;38(4):291-297

https://doi.org/10.5271/sjweh.3308

Published online: 07 Jun 2012, Issue date: 01 Jul 2012

Worktime control: theoretical conceptualization, current empirical knowledge, and research agenda

by Beckers DGJ, Kompier MAJ, Kecklund G, Härmä M

Affiliation: Radboud University Nijmegen, Behavioural Science Institute, PO Box 9104, $6500 \mathrm{HE}$, Nijmegen, The Netherlands. d.beckers@psych.ru.nl

Refers to the following texts of the Journal: 2011;37(4):263-275

2011;37(3):173-185 2011;37(4):276-287 2012;38(4):343-348

2012;38(4):380-390 2012;38(4):337-342 2012;38(4):327-336

2012;38(4):314-326 2012;38(4):299-313 2006;32(6):421-430

2010;36(2):81-84 2008;34(3):198-205 2008;34(1):1-3

2006;32(6):502-514

The following article refers to this text: 2015;41(4):347-355

Key terms: editorial; self-rostering; self-scheduling; stress; well-being; work scheduling; work-family conflict; work-non-work balance; worktime control; worktime flexibility

This article in PubMed: www.ncbi.nlm.nih.gov/pubmed/22678526

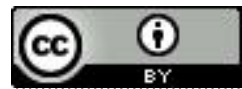




\section{Worktime control: theoretical conceptualization, current empirical knowledge, and research agenda}

Working hours play a crucial role in the life, health, and well-being of workers. Concerning irregular working hours, the recent Fifth European Working Conditions Survey (1) shows that night work is carried out by $19 \%$ and shift work by $17 \%$ of all workers in Europe. More than half of the total workforce works at least one day during the weekend and $21 \%$ works "on call". The health effects of night and shift work have been a popular and important area of research within Scandinavian Journal of Work, Environment \& Health (eg, 2-4), including new and interesting data and a consensus statement on shift work and breast cancer (5) published in this issue (5-8). As working times are becoming increasingly irregular and flexible, their associations with work-life balance, work satisfaction, mental health, and productivity are of growing interest.

Regarding worktime flexibility, the literature distinguishes between company-based and employeeoriented flexibility (9-13). The former refers to "the need of employers to extend, modify, or reduce work hours according to client or production needs" (10, p503). Shift work and mandatory overtime are well-known examples. Employee-oriented worktime flexibility refers to autonomy regarding working times with the aim of meeting employee needs (14). A similar construct is worktime control (WTC): "an employee's perception of his/her possibilities to control the duration, position, and distribution of his/her working times" (10, p503). WTC refers to self-determination of worktime aspects such as starting and ending times of the work day, breaks, days off, vacations (9), and control over whether, when and how much to work overtime (15). The distinction between company-based and employee-oriented worktime flexibility is helpful but one must bear in mind that a clear distinction is not always possible: although scholars tend to present WTC as a form of employee-oriented flexibility, it may also be implemented to advance organizational needs, such as higher work motivation and productivity and lower absenteeism and turnover of valued employees (16).

Applications of worktime flexibility are by no means new phenomena. Company-based shift work has been a health issue in Europe since the end of the $19^{\text {th }}$ century (17). WTC was pioneered at a German company in 1967, in the form of "gliding time" (cf. flextime). This early experiment resulted in favorable organizational outcomes and, from 1970 onwards, flextime spread in West-European countries (18). Yet, until the late $20^{\text {th }}$ century, patterns of work schedules remained quite uniform, and work hours were still mainly determined by the employer with limited freedom on the part of employees $(11,18)$. During the 1990s, major trends towards enhanced employee-oriented WTC emerged. This was a reaction to the louder call for "healthy work" and the rising labor participation of women and associated challenges regarding successfully combining work and family (11).

In the $21^{\text {st }}$ century, the trend towards more flexible worktime practices continues. Many organizations aim at flexible worktime arrangements that combine company-based and employee-oriented flexibility. An interesting example of a relatively new and intense flexible worktime intervention is self-scheduling, mostly applied in shift work settings. The employer defines the number of workers needed for several specific time units (eg, for each hour of each working day over a specific time period) and employees can then choose their own working hours by signing up for specific time units, thereby taking into account their personal preferences, worktime regulations, and the minimum number of work hours they have to work according to their contract. Another flexible worktime practice that has gained popularity 
is "boundaryless work" - also known as "trust hours" (13) - which basically combines intensive employee WTC and spatial flexibility among white-collar workers. As a consequence, the traditional work day characterized by 8 hours of work, 8 hours of free time, and 8 hours of sleep, might be replaced by a different time structure in which work and private life are much more integrated. A well-known symptom of such integration is that many contemporary workers stay in contact with work during evenings, days off, weekends, and vacations, which is in some cases even expected by their employers.

Not only individual employers and employees are increasingly engaged in promoting employee WTC, also several European countries (eg, UK and Scandinavian countries) stimulate WTC by introducing national legislation that enables employees to request employee-oriented flexible working times (12). In The Netherlands, such legislation is currently proposed to be included in the Dutch Work Directive.

All in all, these efforts at multiple societal levels have led to a considerable prevalence of employee WTC in many European countries. A recent international survey among 27000 European companies showed that $57 \%$ of all European companies applied some type of flextime arrangement. This marks a vast increase over the 48\% in 2004 (19). WTC is most prominent in North-European companies: $60-80 \%$ of all companies within Finland, Denmark, Sweden, UK, and Germany indulge flextime. It is less pronounced in East Europe [circa 33\%; (19)].

Against this background, the Scandinavian Journal of Work, Environment \& Health decided to publish a thematic issue on WTC. The aim is to provide an overview of current scientific knowledge about the effects of WTC on employee- and organizational outcomes and advance knowledge on the effects of selfscheduling. In this editorial, we briefly summarize relevant theoretical and empirical insights regarding WTC. We also introduce a research agenda.

\section{Theoretical insights and empirical findings on the effects of worktime control}

Theoretical groundings for the assumed benefits of increased WTC for both employees and organizations stem from several motivational and occupational health theories. From the perspective of Effort-Recovery Theory (20), WTC can be assumed to promote a favorable balance between effort and recovery as it stimulates internal recovery opportunities, by means of control over breaks, and external recovery, as employees can adjust their working and recuperation time to their current need for recovery. Three other key occupational health theories [ie, Self-Determination Theory (21), the Job Characteristics Model (22), and the Job Demands-Control Model (23)] suggest that WTC - as a subdimension of general autonomy - may stimulate worker motivation, health, and performance, and may prevent stress, absenteeism, and turnover. WTC can influence these outcomes by means of at least two processes: (i) through the actual utilization of WTC and associated change in working times and related work characteristics; and (ii) the mere opportunity to self-determine working hours may stimulate favorable outcomes, irrespective of an actual change in working times (this could be called a "psychological process"). Finally, based on theories of work-home interaction (24), WTC can be expected to advance a better work-non-work balance (and thus prevent stress), as WTC enables the adjustment of working time to meet obligations, needs, and activities in private life.

Following such theoretical insights, Baltes and colleagues (16) decided to empirically substantiate whether flextime interventions indeed stimulate favorable organizational outcomes. In a meta-analysis of 27 intervention studies, these authors concluded that flextime (ie, employee control over starting and ending times of the work day) can have positive effects on organizational outcomes (ie, productivity, job satisfaction, absenteeism, and satisfaction with work schedule). However, differences in effect sizes were found, indicating that flextime is more likely to impact attendance (absenteeism) than directly impact worker effectiveness (productivity). 
In the first contribution of this thematic issue, Nijp and colleagues (15) build upon this meta-analysis. They systematically review the scientific literature - published between 1995 and 2011 - on the association between the broad concept of WTC on the one hand (general as well as several specific aspects of WTC, eg, flextime and leave control) and employee- and organizational outcomes on the other. Their review shows that there is (moderately) strong evidence for a positive association between WTC and work-non-work balance. Moreover, there are indications for favorable associations with indicators of health, well-being, and job-related outcomes, but more longitudinal and intervention research is needed to draw definite conclusions about causal effects.

Contemporary knowledge on the effects of self-scheduling was discussed in a recent Cochrane review on flexible working conditions (12) and within the review by Nijp and colleagues (15). The scarce empirical research in this field provides mixed findings. In some studies, for some health-related outcomes, significant changes were found after the introduction of self-scheduling [eg, significant decrease in systolic blood pressure (25) and in tiredness during the night shift (26), and a favorable change in work-life balance and job satisfaction (27)]. For other outcomes or within other studies, no significant changes were reported after implementation of self-scheduling [eg, no significant changes in diastolic blood pressure and sleepiness (25), mental health (26), somatic symptoms (27), stress, work-family conflicts, and biomarkers of cardiovascular disease (28), or sleep (29)]. Based on these findings, the authors of both reviews cautiously conclude that the introduction of self-scheduling can have favorable effects, but more intervention research is urgently needed to understand fully the effects of different types of selfscheduling on distinct outcome categories $(12,15)$. The current thematic issue contains two studies on self-scheduling $(30,31)$ that present valuable new insights into the process factors behind self-scheduling and changes in work and well-being characteristics following the introduction of self-scheduling.

For now, it seems safe to conclude that WTC has the potential to enhance health, well-being, worknon-work balance, and organizational outcomes. Yet, experts emphasize many limitations of previous research and gaps in knowledge that need to be addressed to understand fully under what circumstances WTC interventions (eg, self-scheduling) will result in favorable employee and organizational outcomes.

\section{A research agenda}

Initiate research with proper designs: The majority of previous WTC studies applied a cross-sectional design (cf. 15). As the limitations of cross-sectional studies with respect to causal inferences are wellrecognized, our first appeal is to conduct more well-designed intervention studies on WTC. The current popularity of WTC applications in organizations creates a window of opportunity for researchers to look into such natural experiments. Since methodological rigor stimulates more valid causal inferences, intervention research should build upon a proper study design (at least pre- and post-measurements of central study variables and comparison of experimental and control groups over time). As previous intervention research suggests that health and organizational effects of increased WTC may diminish over time (16), intervention studies should not only assess short-term effects (eg, 1-6 months after the intervention) but also evaluate longer-term impact.

As we encourage WTC researchers to apply an intervention design, we formulate five suggestions with respect to the content and focus of future WTC intervention research.

Assess whether there is a need for the intervention: Prior to any intervention, researchers should establish whether there is need for change. This needs-assessment should be twofold. First, one should assess whether pre-intervention levels of WTC, health, and/or well-being are low in absolute terms. In this regard, we advise to not merely apply a general assessment of available WTC but rather to examine the present level of multiple subdimensions of WTC [eg, control over starting and ending times of the 
workday, overtime, days off, breaks, and the entire work schedule; cf. (11)]. Second, there should also be a pre-intervention assessment of the subjective individual need for higher levels of each subdimension of WTC, ie, regardless of the absolute level of WTC, researchers should assess whether employees are satisfied with the current level of WTC. If either of these assessments confirms a need for change, a WTC intervention is warranted.

Study the intervention content: For a valid understanding of the potential health and organizational effects after a WTC intervention, researchers must portray the precise content of the worktime control intervention (ie, describe what was planned and what actually happened). It is an illusion to believe that there is only one type of self-scheduling, flextime, or boundaryless work, and - as such - it is necessary to elucidate the specific characteristics of any intervention. This will help to establish what type of WTC intervention ascertains the most favorable effects.

Related to this, it is also crucial to examine whether the applied WTC intervention indeed elicits a change in WTC [ie, manipulation check: comparison of pre- and post measurements of WTC; cf. $(26,28$, 29)]. After all: a specific WTC intervention can be theorized to stimulate WTC, but this may not be evident in practice [cf. program failure (32)]. For example, one of the studies of this special issue indeed shows that self-scheduling individuals reported only moderate average scores on WTC and that personal fit (ie, the association between preferred and actual work hours) was present but not large in magnitude (30).

Regarding the post-intervention assessment of WTC, we advise researchers also to assess to what extent employees actually use their possibilities to self-determine working times and consequently change their actual working times. This assessment may provide more insight into the mechanisms behind the potential association between WTC and health-related or organizational outcomes (ie, "actual usage and change in work hours" versus "the psychological effect of the mere availability of WTC"). Both processes include higher perceived autonomy over working times, but assessment of actual utilization of WTC may show which mechanism is more prominent. One could imagine that for some outcome variables (eg, work-non-work balance), actual utilization is most important, whereas for other outcome variables (eg, work motivation) having the possibility to change working times is sufficient to establish beneficial effects.

Assess the intervention process: Intervention effects are not only determined by the intervention content but also by the way it is implemented, designed, and managed [process-related factors; $(33,34)$ ]. Many previous intervention studies do not provide insight into process factors and therefore little is known on the implementation process, contextual factors, and the aim and rationale for interventions (12). Yet, ignored process factors may have an important influence on the effects of an intervention. For instance, employees' attributions about the aim of a human resource practice (in this case: a WTC intervention) may be of great significance to employee attitudes towards the intervention (eg, in terms of resistance to change) and may partly determine organizational performance after the implementation (35). Future intervention research should therefore include information on process factors, such as: (i) the aim of the intervention and employees' attributions of the aim; (ii) the steps that were undertaken to introduce the intervention; (iii) the level of organizational, supervisory, and employee support (or resistance) regarding the intervention; and (iv) whether supervisors and/or employees were trained to learn how to apply the new work method or related software, etcetera.

Knowledge about the content and process factors of a WTC intervention will help to establish not merely whether a WTC intervention is effective, but under what specific circumstances a specific WTC intervention is effective for which specific outcome variables (36).

Perform subgroup analyses: Only examining overall effects for all employees may obscure subgroup effects and may lead to an erroneously pessimistic conclusion about the effectiveness of WTC interven- 
tions. Favorable effects of an increase in WTC may be most (or even only) evident among workers who experience problems with their pre-intervention health or working hours (eg, the group with high need for WTC). It can be hypothesized that especially employees with relatively high obligations in private life (eg, parents of young children) and employees with a higher need for recovery (eg, some subgroups of older or chronically ill employees) may benefit most from increased WTC. In line with this, previous research found WTC to be mostly beneficial for women who combined fulltime employment with long domestic working hours (37-39). Regarding subgroup analyses, we also advise to elucidate the percentage of workers that experienced a change in WTC and compare these change groups with stable (low and high) WTC groups regarding indicators of well-being, health, and performance over time [cf. $(40,41)$ ].

Avoid a biased focus on positive effects: Traditionally, occupational health research shows a biased focus on adverse consequences of work (42). It is encouraging to see that previous WTC research has focused on potential favorable outcomes. Yet, a caveat is in place: a one-sided focus on "only" positive effects may conceal that applications of WTC may also entail negative side-effects on psychosocial- and time-related work characteristics (36). For instance, self-scheduling can be hypothesized to result in a better work-nonwork balance (as employees can adjust their working times to their responsibilities in private life), but it may also result in more "unhealthy work schedules". The common organizational practice of "better pay for unhealthier work shifts" may stimulate some employees to prefer long sequences of night shifts or many weekends in a row. In this respect, it is good to learn that Garde et al (31) demonstrate that the implementation of self-scheduling did not compromise general recommendations for "healthy shift work design". Nevertheless it is important that researchers pay attention to potential "unhealthy" choices and the role of related changes in pay level and financial incentives. Also, from a primary prevention point of view, selfscheduling software should be designed in such a way that unhealthy choices are prohibited.

In the paper by Ingre and colleagues (30) also other potential problems associated with selfscheduling are identified: (i) lower predictability and regularity in work hours that challenge successful integration of work and private life (especially if preferred rosters are not granted); (ii) competition and conflicts among colleagues for the "best shifts" (with the risk of less assertive employees always losing the battle), and (iii) well-established work teams being shattered by the new individualistic scheduling.

Anecdotal evidence shows that implementation of boundaryless work not only implies more WTC and spatial flexibility, but frequently also an emphasis on performance management and virtual contact possibilities. Specifically this combination of work characteristics may result in higher job demands and overtime work (13), less time for recovery, and more difficulties with psychological detachment from work. Spatial flexibility may also imply less optimal work ergonomics and a possible risk for musculoskeletal problems and repetitive strain injury among computer workers.

These examples emphasize the need for a balanced evaluation of potential positive and potential negative effects of WTC applications on the work environment and on health and performance.

\section{Thematic issue}

Considering the recommendations above, we believe that the topic of WTC and its many applications to be a fruitful ground for at least another decade of research. With the current thematic issue, we aspire to make a valuable contribution to the contemporary knowledge and literature. As such, this issue starts with a systematic review study on the association between WTC and employee as well as organizational outcomes (15), followed by two studies on the practice of self-scheduling $(30,31)$.

After reading this thematic issue, we hope that researchers will be inspired to initiate high quality research on the topic of WTC and working time in general, as this research will not only have a clear theoretical and empirical contribution, but may also help employees, employers, and organizations in practice. 


\section{References}

1 Fifth European Working Conditions Survey. European Foundation for the Improvement of Living and Working Conditions. Luxembourg: Publications Office of the European Union, 2012.

2. Härmä M \& Kecklund G. Shift work and health - how to proceed? Scand J Work Environ Health. 2010;36(2):81-84. http:// dx.doi.org/10.5271/sjweh.2902.

3. Wagstaff AS, Sigstad Lie J-A. Shift and night work and long working hours - a systematic review of safety implications. Scand J Work Environ Health. 2011;37(3):173-185. http://dx.doi.org/10.5271/sjweh.3146.

4. Van Drongelen A, Boot CRL, Merkus SL, Smid T, van der Beek AJ. The effects of shift work on body weight change - a systematic review of longitudinal studies. Scand J Work Environ Health. 2011;37(4):263-275. http://dx.doi.org/10.5271/ sjweh.3143.

5. Bonde JP, Hansen J, Kolstad HA, Mikkelsen S, Olsen JH, Blask DE, Härmä M, Kjuus H, de Koning HJ, Olsen J, Møller M, Schernhammer ES, Stevens RG, Åkerstedt T. Work at night and breast cancer - report on evidence-based options for preventive actions. Scand J Work Environ Health. 2012;38(4):379-390. http://dx.doi.org/10.5271/sjweh.3282.

6. Puttonen S, Viitasalo K, Härmä M. The relationship between current and former shift work and the metabolic syndrome. Scand J Work Environ Health. 2012;38(4):343-348. http://dx.doi.org/10.5271/sjweh.3267

7. Wirtz A, Lombardi DA, Willetts JL, Folkard S, Christiani DC. Gender differences in the effect of weekly working hours on occupational injury risk in the United States working population. Scand J Work Environ Health. 2012;38(4):349-357. http://dx.doi.org/10.5271/sjweh.3295.

8. Oyama I, Kubo T, Fujino Y, Kadowaki K, Kunimoto M, Shirane K, Tabata H, Sabanai K, Nakamura T, Matsuda S. Retrospective cohort study of the risk of impaired glucose tolerance among shift workers. Scand J Work Environ Health. 2012:38(4):337-342. http://dx.doi.org/10.5271/sjweh.3297.

9. Costa G, Åkerstedt T, Nachreiner F, Baltieri F, Carvalhais J, Folkard S, Frings Dresen M, Gadbois C, Gartner J, Grzech Sukalo H, Härmä M, Kandolin I, Sartori S \& Silverio J. Flexible working hours, health, and well-being in Europe: some considerations from a SALTSA project. Chronobiology International. 2004;21: 831-44. http://dx.doi.org/10.1081/CBI200035935 .

10. Härmä M. Workhours in relation to work stress, recovery and health. Scand J Work Environ Health. 2006;32:502-514. http://dx.doi.org/10.5271/sjweh.1055.

11. Ala-Mursula L. Employee worktime control and health [Dissertation]. Oulu University Press: Oulu; 2006.

12. Joyce K, Pabayo R, Critchley JA, Bambra C. Flexible working conditions and their effects on employee health and wellbeing. Cochrane Database Syst Rev. 2010, Issue 2. Art. No.: CD008009. DOI: 10.1002/14651858.CD008009.pub2. http://dx.doi.org/10.1002/14651858.CD008009.pub2.

13. Åkerstedt T \& Kecklund G. The future of work hours - the European view. Ind Health. 2005;43: 80-84. http://dx.doi. org/10.2486/indhealth.43.80.

14. Knauth P. Innovative worktime arrangements. Scand J Work Environ Health. 1998;24 suppl 3: 13-17.

15. Nijp HH, Beckers DGJ, Geurts SAE, Tucker P, Kompier MAJ. Systematic review on the association between employee worktime control and work-non-work balance, health and well-being, and job-related outcomes. Scand J Work Environ Health. 2012;38(4):299-313. http://dx.doi.org/10.5271/sjweh.3307.

16. Baltes B, Briggs TE, Huff JW, Wright JA \& Neuman GA. Flexible and compressed workweek schedules: a meta-analysis of their effects on work-related criteria. J Appl Psychol. 1999; 84: 496-513. http://dx.doi.org/10.1037/0021-9010.84.4.496.

17. Härmä M. Shift work among women — a century-old health issue in occupational health. Scand J Work Environ Health. 2008;34(1):1-3. http://dx.doi.org/10.5271/sjweh.1188.

18. Pierce JL, Newstrom JW, Dunham RB \& Barber AE. Alternative Work Schedules. pp3-51. Massachusetts, USA: Allyn and Bacon, 1989.

19. Kerkhofs M, Román A, Ester P. European Company Survey 2009: Flexibility profiles of European companies. European Foundation for the Improvement of Living and Working Conditions. Luxembourg: Publications Office of the European Union; 2010.

20. Meijman TF, Mulder G. Psychological aspects of workload. In Drenth, Thierry, \& De Wolff, editors. Handbook of Work and Organizational Psychology 2nd ed. Hove (UK): Psychology Press/Erlbaum; 1998. p5-33.

21. Deci EL, Ryan RM. Intrinsic motivation and self-determination in human behavior, New York: Plenum. 1985.

22. Hackman JR \& Oldham GR. Motivation through the design of work. Test of a theory. Org Behavior Human Performance 1976;16:250-79. http://dx.doi.org/10.1016/0030-5073(76)90016-7.

23. Karasek RA \& Theorell T. Healthy work. Stress, productivity and reconstruction of working life. Basic Books, New York, USA; 1990.

24. Geurts S \& Demerouti E. Work-nonwork interface: A review of theories and findings. In: Schabracq MJ, Winnubst JAM \& Cooper CL (Eds.). The Handbook of Work and Health Psychology (pp279-312). Chichester (US): John Wiley \& Sons Ltd; 2003.

25. Viitasalo K, Kuosma E, Laitinen J, Härmä M. Effects of shift rotation and the flexibility of a shift system on daytime alertness and cardiovascular risk factors. Scand J Work Environ Health. 2008;34(3):198-205. http://dx.doi.org/10.5271/ sjweh.1228.

26. Kandolin I \& Huida O. Individual flexibility: an essential prerequisite in arranging shift schedules for midwives. J Nursing Management. 1996;4: 213-7. http://dx.doi.org/10.1111/j.1365-2834.1996.tb00053.x.

27. Pryce J, Albertsen K, Nielsen K. Evaluation of an open-rota system in a Danish psychiatric hospital: a mechanism for 
improving job satisfaction and work-life balance. J Nursing Management. 2006;14:282-8. http://dx.doi.org/10.1111/ j.1365-2934.2006.00617.x.

28. Nabe-Nielsen K, Garde AH, Diderichsen F. The effects of work-time influence on health and well-being: A quasiexperimental intervention study among eldercare workers. International Arch Occup Environ Health; 2011;84:683-695. http://dx.doi.org/10.1007/s00420-011-0625-8.

29. Garde AH, Nabe-Nielsen K, Aust B. Influence on working hours among shift workers and effects on sleep quality: an intervention study. Appl Ergon; 2011;42:238-243. http://dx.doi.org/10.1016/j.apergo.2010.06.011.

30. Ingre M, Åkerstedt T, Ekstedt M, Kecklund G. Periodic self-rostering in shift-work: correspondence between objective work hours, work hour preferences (personal fit), and work schedule satisfaction. Scand J Work Environ Health. 2012;38(4):327-336. http://dx.doi.org/10.5271/sjweh.3309

31. Garde AH, Albertsen K, Nabe-Nielsen K, Carneiro IG, Skotte J, Hansen SM, Lund H, Hvid H, Hansen AM. Implementation of self-rostering (the PRIO-project): effects on working hours, recovery, and health. Scand J Work Environ Health. 2012;38(4):314-326. http://dx.doi.org/10.5271/sjweh.3306.

32. Kristensen, T.S. Intervention Studies in Occupational Epidemiology. Occup Environ Med. 2005;62:205-210. http://dx.doi. org/10.1136/oem.2004.016097

33. Holman D, Wood S. The new workplace: an introduction. In: Holman D, Wall TD, Clegg CW, Sparrow P, Howard A, editors. The new workplace: a guide to the human impact of modern working practices. Chichester (UK): John Wiley \& Sons; 2003. p3-15.

34. Kompier MAJ. New systems of work organization and workers health. Scand J Work Environ Health. 2006;32:421-430. http://dx.doi.org/10.5271/sjweh.1048.

35. Nishii LH, Lepak DP \& Schneider B. Employee attributions of the "why" of HR practices: Their effects on employee attitudes and behaviors, and customer satisfaction. Personnel Psych. 2008;61:503-545. http://dx.doi.org/10.1111/j.17446570.2008.00121.x.

36. Semmer, NK. Job Stress Interventions and Organization of Work. In: Campbell Quick \& Tetrick (Eds.) Handbook of Occupational Health Psychology, 2nd ed. Washington, DC: APA; 2011. p299-318.

37. Ala-Mursula L, Vahtera J, Kivimäki M, Pentti J. Employee control over working times: associations with subjective health and sickness absences. J Epidemiol Community Health. 2002;56: 272-8. http://dx.doi.org/10.1136/jech.56.4.272.

38. Ala-Mursula L, Vahtera J, Pentti J, Kivimäki M. Effect of employee worktime control on health: a prospective cohort study. Occup Environ Med. 2004;61: 254-61. http://dx.doi.org/10.1136/oem.2002.005983.

39. Ala-Mursula L, Vahtera J, Linna A, Pentti J, Kivimäki M. Employee worktime control moderates the effects of job strain and effort-reward imbalance on sickness absence: the 10-Town study. J Epidemiol Community Health 2005;59: 851-7. http://dx.doi.org/10.1136/jech.2004.030924.

40. De Lange AH, Kompier MAJ, Taris TW, Geurts SAE, Beckers DGJ, Houtman ILD \& Bongers PM. A hard day's night: a longitudinal study on the relationships among job demands and job control, sleep quality and fatigue. J Sleep Res. 2009;18, 374-383. http://dx.doi.org/10.1111/j.1365-2869.2009.00735.x.

41. Finne LB, Knardahl S, Lau B. Workplace bullying and mental distress - a prospective study of Norwegian employees. Scand J Work Environ Health. 2011; 37(4):276-287. http://dx.doi.org/10.5271/sjweh.3156.

42. Beckers DGJ, Van der Linden D, Smulders PGW, Kompier MAJ, Van Veldhoven MJPM, Van Yperen NW. Working overtime hours: relations with fatigue, work motivation, and the quality of work. J Occup Environ Med. 2004;46, 1282-1289.

\section{Debby GJ Beckers and Michiel AJ Kompier \\ Radboud University Nijmegen \\ Behavioural Science Institute \\ PO Box 9104, 6500 HE, Nijmegen}

The Netherlands

d.beckers@psych.ru.nl

m.kompier@psych.ru.nl
Göran Kecklund

Stress Research Institute

Stockholm University

SE 10691 Stockholm

Sweden

goran.kecklund@stressforskning.su.se
Mikko Härmä

Finnish Institute of

Occupational Health

Topeliuksenkatu 41a A

FI 00250 Helsinki, Finland

mikko.harma@ttl.fi 
